\title{
CMEARTICLE
}

\section{Mental health and psychosocial support during healthcare emergencies - COVID-19 pandemic}

Hui Shan $\underline{\operatorname{Sim}}^{1}$, MD, GDFM, Choon How $\underline{H o w}^{1,2}$, MMed, FCFP

\begin{abstract}
Janet visited your clinic for a cough of three days' duration. She asked for some sleeping pills, as she had not been sleeping well after she started working from home last month due to movement restriction measures to limit the spread of coronavirus disease 2019 (COVID-19). She said she was worried about her job stability and her family or herself catching COVID-19. She also had to cope with increased household chores in the past month.
\end{abstract}

\section{WHAT IS THE COVID-19 PANDEMIC?}

COVID-19 (coronavirus disease 2019) is predominantly a respiratory illness caused by the severe acute respiratory syndrome coronavirus 2 (SARS-CoV-2), which was previously known as the 2019 novel coronavirus. The illness was first noticed in late 2019 and soon spread around the world, causing widespread mortality with case fatality rates of $0.06 \%$ in Singapore, $1.37 \%$ in Australia $14.5 \%$ in Italy and $19.1 \%$ in France in late June $2020 .{ }^{(1)}$ In mid June, five months after the alarm about SARS-CoV-2 was first raised, there were more than 8.65 million confirmed cases and 460,000 deaths worldwide, with numbers still rapidly rising in some countries. ${ }^{(1)}$ As of 21 June 2020, Singapore has confirmed more than 41,800 cases of COVID-19 and had 26 deaths over the same period. ${ }^{(2)}$

The route of transmission and infectivity period of COVID-19 are still being understood. ${ }^{(3)}$ The main mode of transmission is via respiratory droplets from coughs, sneezes and speech onto mucous membranes. Touching a contaminated surface followed by the mucous membranes may contribute to transmission. Airborne transmission is also a risk in aerosol-generating procedures such as airway intubation and nebulisation. The incubation period is up to two weeks with a median of five days. The infectiousness of the virus is high 2.3 days prior to the onset of symptoms and declines after 7-10 days of symptoms. ${ }^{(3,4)}$ In a subset of asymptomatic patients, infectivity is likely to be lower based on our understanding of the route of transmission.

The pandemic has resulted in far-reaching changes and impact on society. Many countries have implemented and even mandated the use of face masks, physical distancing and movement restriction measures, including closure of businesses, schools and care centres, working from home, and even the lockdown of entire cities and provinces. Many in the general population are worried about their income and even their daily meals. The world is also preparing for a prolonged economic depression.

\section{HOW RELEVANT IS THIS TO MY PRACTICE?}

There is much anxiety and fear due to the high infectivity, severe morbidity and mortality, uncertainty, and changing knowledge and information brought about by this new virus. Measures to mitigate damage such as protective equipment and movement restriction measures, including social isolation and business closures, affect everyone and have caused considerable stress. Other man-made sources of stress include stigmatisation, the spread of false information and scams.

Healthcare providers and systems have also had to rapidly adapt to the situation by adopting new safety protocols and acquiring protective equipment, new knowledge and new information about the pandemic and response measures. We also had to handle new or greater work responsibilities, while some have been compelled to stop non-essential medical services. Some healthcare providers may also face stigmatisation from the public.

This article focuses on mental health and psychological support, which are often neglected or lacking during and after healthcare emergencies. ${ }^{(5)}$ Attention to psychosocial support during crises is important, as better mental health is associated with positive outcomes such as improved physical health, productivity, relationships and social network. ${ }^{(6)}$

\section{WHAT CAN I DO IN MY PRACTICE?}

A holistic clinical approach helps us to recognise the stress that everyone faces.

\section{Screening and recognising the need for psychosocial support}

In view of the widespread impact that healthcare emergencies exert on the population, it is prudent to - before, during and even after the crisis - screen and look out for patients who may need psychosocial support.

People at risk include those who have suffered from COVID-19 or whose family members were infected, and those whose income or 


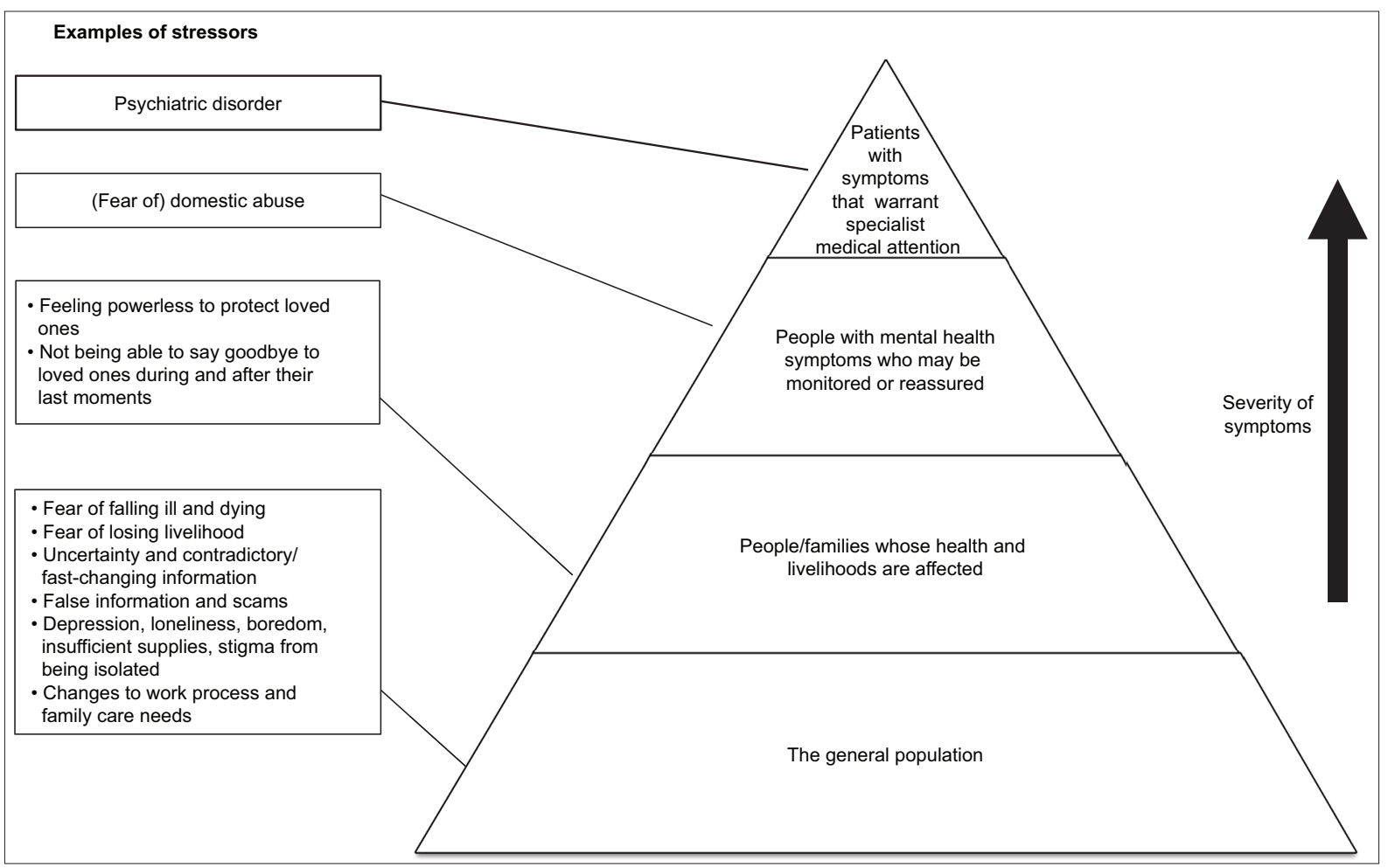

Fig. 1 Pyramid representation shows the spectrum of the population that requires mental health and psychosocial support as well as some examples of mental health stressors. The majority of the population have mild psychological symptoms and form the base of the pyramid. The pyramid tapers towards the top, with the number of people decreasing as the severity of symptoms increases. These levels and demarcations are not rigid and are for illustrative purposes.

basic needs have been affected. Patients with a history of psychiatric disorders such as anxiety, depression and substance abuse are also predisposed to coping difficulties. Furthermore, there is a greater risk of domestic abuse during emergencies, especially with movement restriction measures during COVID-19. ${ }^{(7-9)}$ Examples of screening tools include the Patient Health Questionnaire-2 (i.e. PHQ-2) for depression and the seven-item Generalised Anxiety Disorder scale.

\section{Assessing the level of need and management required}

Psychological first aid ${ }^{(10)}$ is a non-intrusive, practical intervention that a trained individual from any walk of life can use to help stabilise the affected person. All frontline workers should be trained in psychological first aid. First, determine the safety of both the psychological first aider and the affected person. Second, ensure that emergency or urgent needs are attended to before commencing psychological first aid. Examples include life-threatening conditions, basic need for food and shelter, and psychological red flags that require urgent specialist attention. After making sure that the first two conditions are met, we can attempt to help the people who may need support: ask them about their needs and concerns, and listen to them. Do not pressurise them to speak, instead giving them the time and space to share. Normalising stress and allowing silence may be useful in some situations. Having heard them, help them to feel calm and to problem solve, link them to useful information, resources and services, and help them to connect with loved ones and social support. Identify the level of mental health need (Fig. 1) based on patients' risk factors and the extent of their psychological symptoms and dysfunction in order to manage them with the relevant level of support (Fig. 2).
Examples of psychosocial stressors and support/interventions are found in Fig. 1 and Fig. 2, respectively.

Having a keen knowledge of existing formal and informal resources can be very useful, including patients' family and friends; fellow colleagues or professionals; community leaders; schools; centres for the elderly, the youth and the vulnerable (e.g. those with disabilities); social workers; and the healthcare system. Some mental health and psychosocial support helplines including online counselling options in Singapore are listed in Box 1.

Self-care and healthy coping strategies are important and applicable to all individuals. These include healthy diet, sleep, physical and relaxation exercises, maintenance of social contact, avoidance of unhealthy habits (e.g. spending too much time looking for information on the outbreak), and avoidance of unhealthy substances such as tobacco, alcohol and other drugs to cope with one's emotions. Some people may be able to draw on life skills and experience gained from previous adversity to help them cope with the present situation. For those who are unaccustomed to accepting or seeking help and support, we can advise that it is normal for people to require support from one another during a crisis and that taking good care of oneself is a form of responsibility towards others.

The following five principles have been found to be helpful in psychosocial interventions. ${ }^{(11,12)}$ In applying these principles, we should also be mindful of the culture of the affected person. We should foster a sense of: (a) safety - educating people on what they are dealing with (e.g. a viral infection) and how to protect themselves; (b) self and community empowerment - help people learn how to inform and equip themselves with reliable information and how to seek help (Box 1); (c) connectedness - 


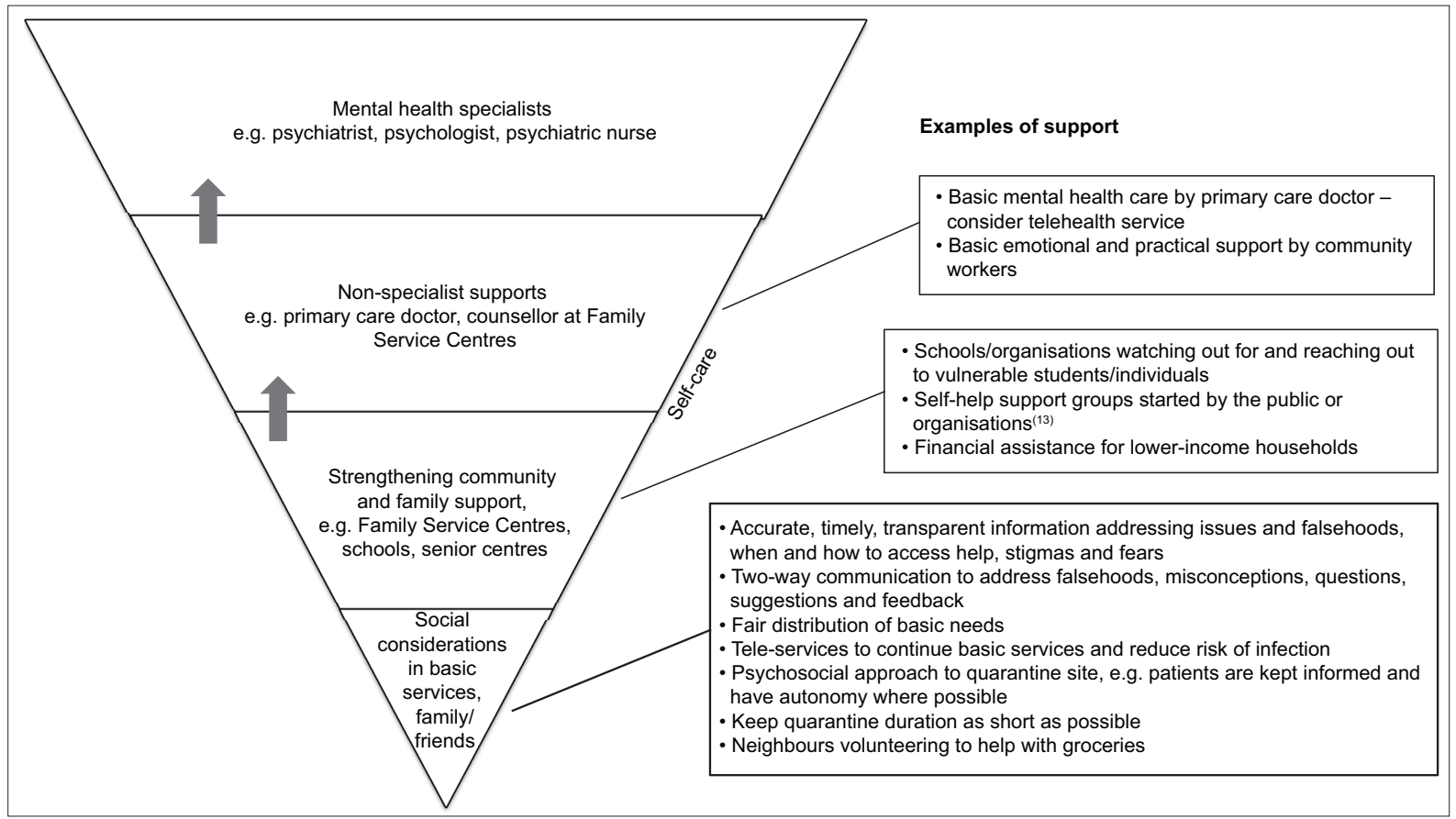

Fig. 2 Inverse pyramid representation shows the amount of mental health resources typically used to attend to the needs of the population and some examples of psychosocial intervention. Self-care is important and applicable to everyone. Arrows: refer if red flags noted.

Box 1. Mental health and psychosocial support helplines in Singapore (accessed 29 June 2020):

- List of helplines: https://go.gov.sg/helplines

- National Care Hotline: 18002026868

\section{Mental well-being}

- Fei Yue's Online Counselling Service: http://www.ec2.sg

- Institute of Mental Health's Mental Health Helpline: 63892222

- Samaritans of Singapore: 18002214444

- Silver Ribbon Singapore: 63853714 (http://www.

silverribbonsingapore.com)

- Men's Helplink via email and Facebook Messenger by The Society

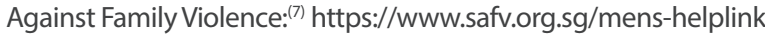

\section{Marital and parenting issues}

- Community Psychology Hub's online counselling platform:

https://www.cphonlinecounselling.sg/hc/en-us

- Location of Family Service Centres: https://www.msf.gov.sg/ dfcs/familyservice

\section{Violence or abuse}

- Big Love Child Protection Specialist Centre: 64450400 (http:// www.biglove.org.sg)

•HEART @ Fei Yue Child Protection Specialist Centre: 68199170 (https://www.fycs.org/our-work/children/community-basedchild-protection-specialist-centre/)

- PAVE's integrated services for individual and family protection: 65550390 (http://www.pave.org.sg)

- Project StART: 64761482 (https://www.carecorner.org.sg/familyviolence)

•TRANS SAFE Centre: 64499088 (https://www.trans.org.sg/services-safe)

\section{Counselling}

-TOUCHLine (counselling): 18003772252 (https://www.touch. org.sg/keeping-our-community-safe)

- Care Corner Counselling Centre: 18003535800

keeping in touch with family and friends/support network (through calls and technology during a movement restriction period), promoting social interaction and activities through outreach activities by care and community centres; (d) calm - reassurance, addressing falsehoods and providing strategies and advice on relaxation and calming techniques using various media including print, television, radio and online videos and apps; and (e) hopepublic communication to focus on what is being done, resources available to help affected people, hopeful messages and stories of people who have overcome their difficulties.

Before discharging patients from a consultation, educate them on red flags that should prompt them to seek help or medical attention and how they can do so.

\section{Monitoring and reviewing patients}

We should review and monitor patients whom we are managing to ensure that our treatment and recommendations are working and to identify red flags that indicate a need to escalate care or seek further help from community partners. Besides face-to-face consults, teleconsultation can be considered for selected patients. It is also good practice to check in with patients whom we have referred for further management in the community or for further psychiatric management.

The periods of movement restriction and the aftermath of the emergency are good times for individuals to examine and reflect on what is important to them, lessons learnt, what was helpful or unhelpful, and how they can and will do better. Likewise, it is helpful for us and for our society to continually review and refine our objectives, processes and systems.

\section{Caring for healthcare and response workers}

Healthcare and response workers have similar mental health and psychosocial needs during healthcare emergencies. Examples of stressors and interventions that are more pertinent to healthcare 
Table I. Examples of stressors and support for healthcare and response workers.

\begin{tabular}{|c|c|}
\hline Stressors & Support \\
\hline \multicolumn{2}{|l|}{ Physical } \\
\hline $\begin{array}{l}\text { - Strict and new procedures and protocols to minimise risk of infection } \\
\text { - Protective equipment causes physical strain and difficulties in communication } \\
\text { and carrying out certain tasks }\end{array}$ & $\begin{array}{l}\text { - Organisation to ensure workplace safety as much as } \\
\text { possible with protocols, procedures and equipment } \\
\text { - Provide fans, cold drinks and ice cream to reduce heat } \\
\text { exhaustion and boost morale }\end{array}$ \\
\hline \multicolumn{2}{|l|}{ Work-related } \\
\hline $\begin{array}{l}\text { - Greater work demands, e.g. longer hours, new or greater scope of work, } \\
\text { covering extra duties for sick/affected colleague } \\
\text { - Lack of sufficient protective equipment }\end{array}$ & $\begin{array}{l}\text { - On-the-job training for people with new or expanded } \\
\text { job scope } \\
\text { - Staff rotation } \\
\text { - Transparent, flexible leadership with timely } \\
\text { communication }{ }^{(14)} \\
\text { - Regular review of staff (including a period after the } \\
\text { emergency) to identify risks and emerging issues and } \\
\text { improve and adjust supportive responses }\end{array}$ \\
\hline \multicolumn{2}{|l|}{ Mental } \\
\hline $\begin{array}{l}\text { - Stigmatisation from the public } \\
\text { - Finding out that a close colleague was a victim can be sad and is a reminder of } \\
\text { one's vulnerabilities } \\
\text { - Emotional stress from having to constantly triage patients and balance medical } \\
\text { resources } \\
\text { - Emotional stress from having to face widespread morbidity and mortality } \\
\text { - Emotional stress from facing dying patients who are not able to see their families } \\
\text { - Onerestimating personal responsibility for poor outcome of patient }{ }^{(15)} \\
\text { stigmatisation or self-imposed quarantine }\end{array}$ & $\begin{array}{l}\text { - Regular debriefs to help monitor psychological status } \\
\text { and facilitate sense of cohesion in a prolonged crisis } \\
\text { - Emails, pamphlets and posters alerting staff to warning } \\
\text { signs of psychological distress and access to support } \\
\text { - Provide online mental health resources } \\
\text { - Provide staff counselling and peer support groups } \\
\text { - Create opportunities for reflection and closure } \\
\text { - Take time to honour a deceased colleague } \\
\text { - Display of appreciation from the public and } \\
\text { organisation }\end{array}$ \\
\hline
\end{tabular}

and response workers are found in Table I. Self-care and healthy coping strategies are crucial. It is advisable to have regular checkin sessions with ourselves or with family and friends to ensure that we do not get overwhelmed. We should also look out for and support one another. Accept and seek help when needed so that we can continue to fulfil our roles well and not worry our loved ones. Although it may not be easy amid the demands brought about by the crisis, we should also aim to reflect regularly and improve ourselves and our systems and processes for better coping and mental health.

The role of the workplace or agency can also make a significant difference to the well-being of workers. The healthcare or response worker may offer feedback or ideas to improve staff or organisational performance and coping. The workplace should institute procedures and equipment to ensure workplace safety and look out for staff who may need additional support, including psychosocial support and on-the-job training for those who may not be familiar with work in the setting of healthcare emergencies or those who have had a change of job scope. Transparent and flexible leadership with timely updates and communication will also help to reassure and empower staff. ${ }^{(14)}$ Other measures that organisations can take to support their staff include staff rotation to reduce burnout and assist with coping; providing online mental health resources in addition to traditional counselling and peer support to increase access to support; showing appreciation for good work; and boosting staff morale during these difficult times.

In Singapore, the Public Health Preparedness Clinics (PHPC) scheme, ${ }^{(16)}$ previously called the Pandemic Preparedness Clinic scheme, is a strategy by the authorities to promote primary care clinic response to public health emergencies. During the COVID-19 pandemic, the PHPCs are supplied with protective equipment and patients can receive medical attention and treatment for respiratory illness at a subsidised rate. Besides equipment and medication supply, the PHPC scheme also provides training and refreshers to help the healthcare provider keep up to date with the skills and knowledge required for an emergency response. The results of the SARS-CoV-2 tests performed by PHPCs and the public institutes are accessible to healthcare providers who have access to the National Electronic Health Record system. Singapore citizens and permanent residents are also able to access their SARS-CoV-2 test result on applications such as HealthHub SG and Health Buddy. These measures may help to allay some of the worries of healthcare providers, patients and the public.

\section{CONCLUSION}

Healthcare emergencies threaten the mental health of many people. We should screen and look out for at-risk patients who may require psychosocial support, which ranges from informal support from family and friends to help from community services, their primary care doctor or specialist psychiatrist attention. The key is to identify the level of support needed and to manage or refer patients as indicated. Patients should be monitored and reviewed to ensure that there is sufficient care and support. During these busy and difficult times, it is also important to take care of our own mental health. 


\section{TAKE HOME MESSAGES}

1. Safeguard the mental health and psychosocial support of patients during healthcare emergencies to promote resilience and better health, productivity and relationships.

2. Screen and look out for patients who may require psychosocial support before, during and even after healthcare emergencies. At-risk patients include those who are affected by the emergency, those who have a history of psychological disorders, and marginalised individuals with poor socioeconomic backgrounds or disabilities.

3. Identify the level of psychosocial support needed for each patient and manage or refer them to the community or specialist psychiatric unit as indicated. Educate the patient on when (i.e. red flags) and how to seek further help. Review patients and adjust the management plan accordingly.

4. Familiarise yourself with support services and systems available in the community and how to refer patients to these services. These include community leaders, schools, centres for the elderly, the youth and the vulnerable (e.g. those with disabilities), social workers, counsellors and healthcare workers.

5. Practise and encourage self-care and healthy coping strategies for all. These include healthy diet, sleep, physical and relaxation exercises, maintenance of social contact, and avoidance of unhealthy habits and substances.

6. Empower patients and help them to feel safe, calm, hopeful and connected to a support system.

You shared with Janet your assessment that her current anxiety and stress levels can be managed with some support from her family. You advised her to manage her insomnia without the use of drugs and pointed her to the HealthHub website for some stress management and relaxation strategies. You suggested that she can share some of her responsibilities with her husband and come up with a schedule for her son. Besides giving her contacts for phone and online counselling helplines, you also directed her to the mycareersfuture.sg and workfare.gov.sg websites to find out more about job opportunities and skills upgrading if she was still worried about her job security. You asked her to visit your clinic again if her respiratory symptoms and anxiety do not improve soon. She agreed with your plan and thanked you for your advice.

\section{REFERENCES}

1. World Health Organization. WHO Coronavirus Disease (COVID-19) Dashboard. Available at: https://covid19.who.int. Accessed June 21, 2020.

2. Ministry of Health Singapore. Updates on COVID-19 (Coronavirus Disease 2019) Local Situation. Available at: https://www.moh.gov.sg/covid-19. Accessed June 21, 2020.

3. McIntosh K. Coronavirus disease 2019 (COVID-19): Epidemiology, virology, and prevention. In: UpToDate [online]. Available at: https://www.uptodate. com/contents/coronavirus-disease-2019-covid-19-epidemiology-virology-andprevention\#H1299415271. Accessed June 18, 2020.

4. Academy of Medicine, Singapore. Position Statement from the National Centre for Infectious Diseases and the Chapter of Infectious Disease Physicians, Academy of Medicine, Singapore - 23 May 2020. Available at: https://www. ams.edu.sg/view-pdf.aspx?file=media\%5C5556_fi_331.pdf\&ofile=Period+of+ Infectivity+Position+Statement+(final) $+23-5-20+(\log 0)$. pdf. Accessed June 18, 2020.

5. Inter-agency Standing Committee. Interim Briefing Note Addressing Mental Health and Psychosocial Aspects of COVID-19 Outbreak (developed by the IASC's Reference Group on Mental Health and Psychosocial Support). Available at: https://interagencystandingcommittee.org/iasc-reference-group-mentalhealth-and-psychosocial-support-emergency-settings/interim-briefing. Accessed June 17,2020

6. World Health Organization. Building back better: sustainable mental health care after emergencies. Available at: https://www.who.int/mental_health/ emergencies/building_back_better/en/. Accessed June 1, 2020.

7. Iau J. Coronavirus: More cases of family violence during circuit breaker; police to proactively help victims. In: The Straits Times [online]. Available at: https://www.straitstimes.com/singapore/courts-crime/coronavirus-morecases-of-family-violence-during-circuit-breaker-police-to. Accessed June 21, 2020

8. Technical Committee on Gender Equality. Domestic Violence and COVID-19. In: United Nations Peacekeeping Force in Cyprus [online]. Available at: https:// unficyp.unmissions.org/domestic-violence-and-covid-19. Accessed June 21, 2020

9. World Health Organization. COVID-19 and violence against women: what the health sector/system can do. Available at: https://www.who.int/ reproductivehealth/publications/emergencies/COVID-19-VAW-full-text.pdf. Accessed June 21, 2020.

10. World Health Organization. Psychological first aid: guide for field workers. Available at: https://www.who.int/mental_health/publications/guide_field_ workers/en/. Accessed June 1, 2020.

11. National Center for PTSD, U.S. Department of Veterans Affairs. For Providers and Community Leaders: Helping People Manage Stress Associated with the COVID-19 Virus Outbreak. Available at: https://www.ptsd.va.gov/covid/ COVID_providers_comm_leaders.asp. Accessed June 14, 2020.

12. Hobfoll SE, Watson P, Bell CC, et al. Five essential elements of immediate and mid-term mass trauma intervention: empirical evidence. Psychiatry 2007; 70:283-369.

13. van Ommeren M, Saxena S, Saraceno B. Mental and social health during and after acute emergencies: emerging consensus? Bull World Health Organ 2005; 83:71-6.

14. Wu PE, Styra R, Gold WL. Mitigating the psychological effects of COVID-19 on health care workers. CMAJ 2020; 192:E459-60.

15. American Psychiatric Association Committee on Psychiatric Dimensions of Disaster and COVID-19. Guidance Document on COVID-19 Death and Dying Exposures: Considerations for Healthcare Workers and Staff Exposed to COVID-19 Death and Dying. Available at: https://www.psychiatry.org/File\%20 Library/Psychiatrists/APA-Guidance-Death-Dying-in-Workplace.pdf. Accessed June 18, 2020

16. Primary Care Pages. Public Health Preparedness Clinic (PHPC). Available at: https://www.primarycarepages.sg/practice-management/moh-national-schemes/ public-health-preparedness-clinic-(phpc). Accessed June 25, 2020. 


\section{SINGAPORE MEDICAL COUNCIL CATEGORY 3B CME PROGRAMME} (Code SMJ 202007A)

1. Mental health and psychological support are often neglected or lacking during and after healthcare emergencies.

2. Better mental health is associated with positive outcomes such as improved health, productivity, relationships and social network.

3. In view of the widespread impact that healthcare emergencies exert on the population, it is not necessary to screen and look out for patients who may need psychosocial support.

4. People at risk of mental health problems during healthcare emergencies include those who have been affected by the disease, those whose basic needs or income have been affected, and those with a history of psychiatric disorders.

5. Psychological first aid cannot be performed by a trained individual from any walk of life.

6. We should only commence psychological first aid after ensuring the safety of both the first aider and the affected person, and after emergency or urgent needs have been attended to.

7. In psychological first aid, after listening to the person's needs and concerns, help them to feel calm and to problem solve, link them to information, resources and services, and help them to connect with loved ones and social support.

8. Identify the level of mental health need based on patients' risk factors and the extent of their psychological symptoms and dysfunction in order to manage them with the relevant level of support.

9. Existing support resources include family and friends, community leaders, schools, centres for the elderly and social workers.

10. There are online counselling helplines in Singapore.

11. Self-care and healthy coping strategies are not for everyone.

12. Unhealthy coping habits include spending too much time looking for information on the disease outbreak.

13. Five principles found to be helpful in psychosocial interventions are fostering a sense of safety, connectedness, calm, hope, and self and community empowerment.

14. We should be mindful of the culture of the person whom we are trying to help in our psychosocial intervention.

15. Before discharging patients, educate them on red flags that should prompt them to seek help or medical attention and how they may do so.

16. Review and monitor patients to ensure that your treatment and recommendations are working and to identify red flags or indications for further help.

17. We should not check on our patients whom we have referred for further management in the community or for further psychiatric management.

18. We should check in with ourselves or with family and friends regularly to ensure that we do not get overwhelmed.

19. The Public Health Preparedness Clinics scheme in Singapore does not provide protective equipment, medication and training for public health emergencies.

20. Staff should be reviewed regularly to identify risks and emerging issues and tweak supportive responses.

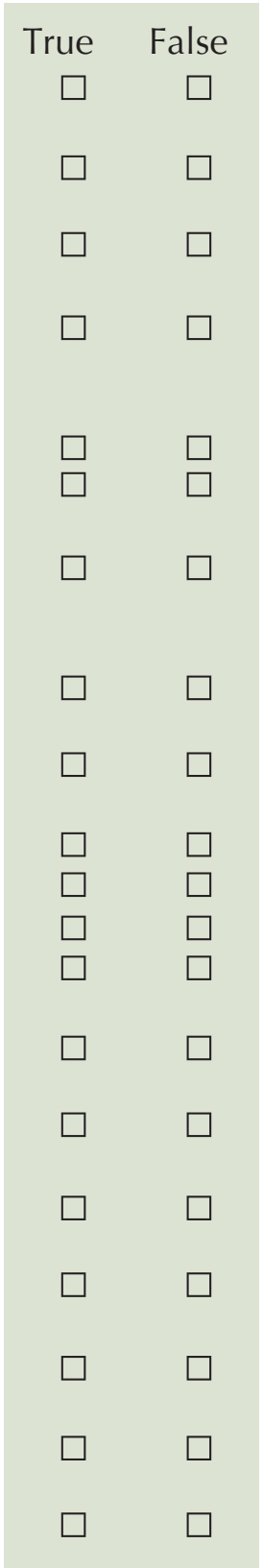

\section{Doctor's particulars:}

Name in full:

MCR no.:

Specialty:

Email:

\section{SUBMISSION INSTRUCTIONS}

Visit the SMJ website: http://www.smj.org.sg/current-issue and select the appropriate quiz. You will be redirected to the SMA login page.

For SMA member: (1) Log in with your username and password (if you do not know your password, please click on 'Forgot your password?'). (2) Select your answers for each quiz and click 'Submit'.

For non-SMA member: (1) Create an SMJ CME account, or log in with your SMJ CME username and password (for returning users). (2) Make payment of SGD 21.40 (inclusive of $7 \%$ GST) via PayPal to access this month's quizzes. (3) Select your answers for each quiz and click 'Submit'.

RESULTS:

(1) Answers will be published online in the SMI September 2020 issue. (2) The MCR numbers of successful candidates will be posted online at the SMJ website by 10 September 2020. (3) Passing mark is $60 \%$. No mark will be deducted for incorrect answers. (4) The SMJ editorial office will submit the list of successful candidates to the Singapore Medical Council. (5) One CME point is awarded for successful candidates. (6) SMC credits CME points according to the month of publication of the CME article (i.e. points awarded for a quiz published in the June 2020 issue will be credited for the month of June 2020, even if the deadline is in August 2020).

Deadline for submission (July 2020 SMJ 3B CME programme): 12 noon, 3 September 2020. 